\title{
Black pleural effusion in melanoma
}

\author{
Wei-Chih Liao MD, Chia-Hung Chen MD, Chih-Yen Tu MD
}

Previously published at www.cmaj.ca

A 71-year-old woman with a history of recurrent melanoma presented with a 20-day history of leftsided chest pain. On physical examination, she was afebrile and her vital signs were normal.

Over her left lower lung field, there was dullness to percussion and she had decreased breath sounds. A chest radiograph was consistent with left pleural effusion (Figure 1A), which was confirmed by ultrasonography. Subsequent thoracentesis yielded a black fluid (Figure 1B). Cytologic examination of the fluid by means of Diff-Quick stain showed melanin pigment deposits within enlarged cells with hyperchromatic nuclei and conspicuous nucleoli (Figure 1C). The diagnosis was melanoma with left-sided malignant pleural effusion. Conservative management with the implantation of a $12-\mathrm{F}$ pigtail catheter helped improve the patient's symptoms within days and she declined further treatment of her metastatic melanoma.

The appearance of pleural fluid is related to its causes. "Serous" and "blood tinged" are the most common descriptions recorded for pleural fluid at thoracentesis. ${ }^{1,2}$ Black pleural effusions have been reported, and are usually related to infection (bacterial or fungal) or hemorrhage. ${ }^{3,4}$ Melanoma metastasizes to the thorax in about $16 \%$ of cases, and of these, malignant pleural effusion (e.g., may be black) is observed in about $2 \% .^{2}$ Metastatic melanoma has also been associated with black ascites. ${ }^{5}$

\section{This article has been peer reviewed.}

Competing interests: None declared.

\section{REFERENCES}

1. Villena V, Lopez-Encuentra A, Garcia-Lujan R, et al. Clinical implications of appearance of pleural fluid at thoracentesis. Chest 2004;125:156-9.

2. Chen JT, Dahmash NS, Ravin CE, et al. Metastatic melanoma in the thorax: report of 130 patients. AJR Am J Roentgenol 1981;137:293-8.

3. Rojas-Solano JR, Light RW, Brenes-Dittel A. Black pleural effusion. Arch Bronconeumol 2009;45:103-4.

4. Lai CC, Liaw SJ, Hsiao YC, et al. Empyema thoracis due to Rhizopus oryzae in an allogenic bone marrow transplant recipient. Med Mycol 2006;44:75-8.

2 5. Murali R, Loughman NT, McKenzie PR, et al. Cytological features of melanoma in exfoliative fluid specimens. J Clin Pathol 2009;62:638-43.

From the Division of Pulmonary and Critical Care Medicine, Department of Internal Medicine, China Medical University Hospital,Taiwan, China

CMAJ 2010. DOI:10.1503/cmaj.091312

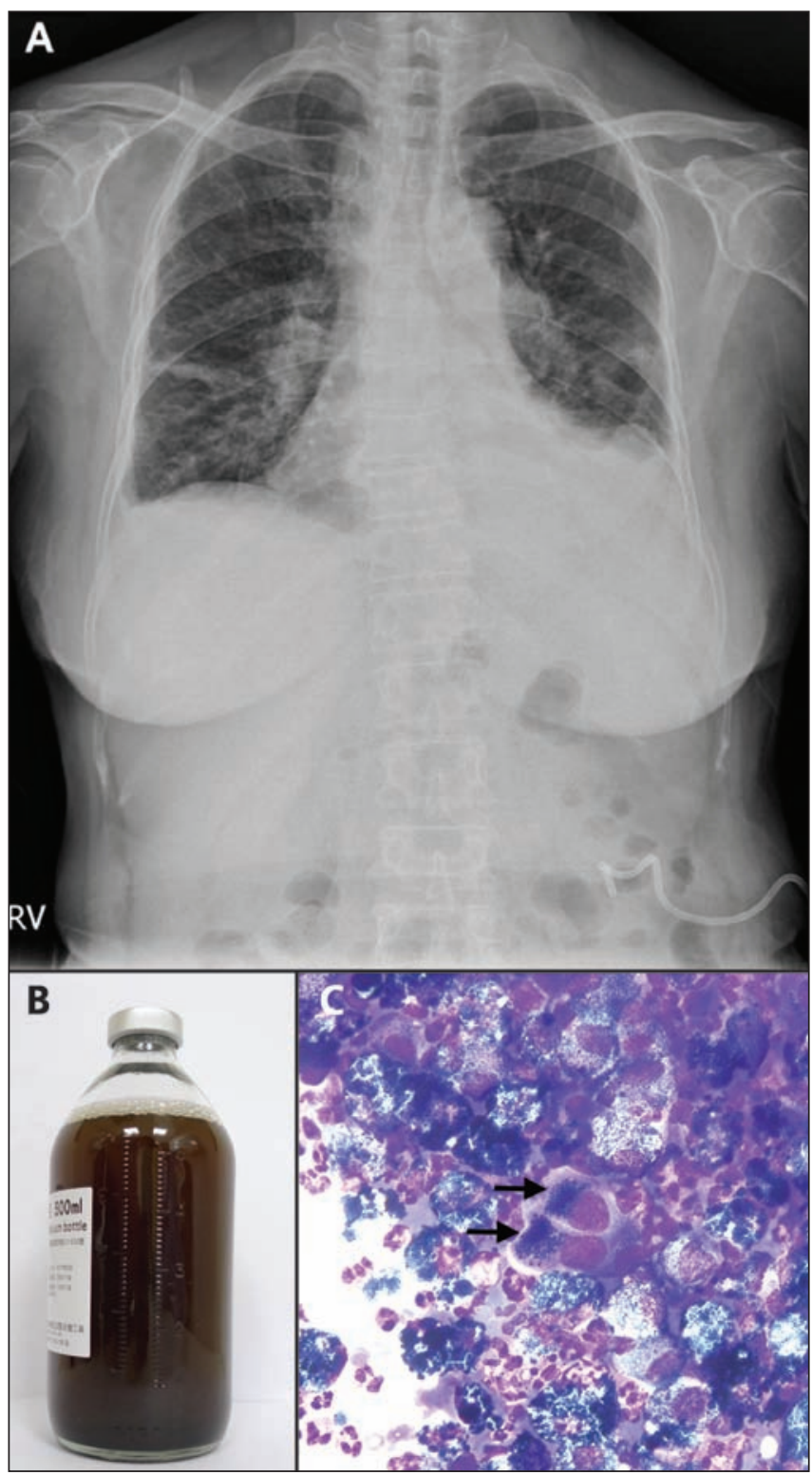

Figure 1: (A) Chest radiograph of a 71-year-old woman, demonstrating a left pleural effusion. (B) Black fluid yielded from chest ultrasonography-guided thoracentesis. (C) Cytologic view of the fluid (Diff-Quick stain, original magnification $\times 400$ ), showing melanin pigment deposits within enlarged cells with hyperchromatic nuclei and conspicuous nucleoli (arrows). 